\title{
Patient Characteristics and Outcome Measurement in a Low Secure Forensic Hospital
}

\section{Longdon, Laura}

Nottinghamshire Healthcare NHS Foundation Trust, Rampton Hospital, Retford, United Kingdom

\section{Edworthy, Rachel}

University of Nottingham, Institute of Mental Health, University of Nottingham Innovation Park, Nottingham, United Kingdom

\section{Resnick, Jeremy}

Nottinghamshire Healthcare NHS Foundation Trust, Wells Road Centre, Wells Road, Nottingham, United Kingdom

\section{Byrne, Adrian}

The University of Manchester, Cathie Marsh Institute for Social Research, Humanities Bridgeford Street, Oxford Road, Manchester United Kingdom

\section{Clarke, Martin}

Nottinghamshire Healthcare NHS Foundation Trust, Institute of Mental Health, University of Nottingham Innovation Park, Triumph Road, Nottingham, United Kingdom.

\section{Cheung, Natalie}

Nottinghamshire Healthcare NHS Foundation Trust, Wells Road Centre, Wells Road, Nottingham, United Kingdom

\section{Khalifa, Najat (Corresponding Author)}

Nottinghamshire Healthcare NHS Foundation Trust, Institute of Mental Health, University of Nottingham Innovation Park, Triumph Road, Nottingham, United Kingdom

Najat.Khalifa@nottshc.nhs.uk 


\begin{abstract}
Background: Health services are increasingly required to measure outcomes after treatment, which can be reported to the funding body and may be scrutinised by the public. Extensive high quality measurements are time consuming. Routinely collected clinical data might, if anonymised, provide good enough evidence of useful change consequent on service received. Research question: Do the Health of the Nation Scale (HoNOS) and the 20 item Historical, Clinical, Risk (HCR-20) structured professional judgement tool scores provide evidence of clinical and risk change among low security hospital patients at 6 and 12 months after admission? Methods: One hundred and eight men were either resident on the unit on $1^{\text {st }}$ January 2011 or new admissions to the census date of $31^{\text {st }}$ May 2013. Their routinely collected data were added to an outcome register following each patient's Care Programme Approach clinical review meeting and analysed using repeated measures t-tests with Bonferroni corrections. Results: Most of the men, mean age 34.3 years, were single (93\%), White British (71\%) and with a primary diagnosis of schizophrenia (62\%). There were significant reductions in the 11item HoNOS (excluding the community living condition scale) scores between baseline and 6 months, and between 6 months and 12 months, but no change on its additional 7-item secure subscale. Individual effect sizes indicated that $39 \%$ of the men had better social function, although $18 \%$ had deteriorated at six months. There was little overall change in the HCR-20; individual effect sizes indicated that 11 men (15\%) were rated as being at lower risk level and $10(14 \%)$ at higher after six months in the study.

Conclusions/implications for clinical practice: Standard clinical measures are promising as indicators of change in low security hospital patients. Risk ratings may be conservative, but, at this stage of a secure hospital admission, higher scores may be as likely to indicate progress in identifying and quantifying risks as apparent increase in risk.
\end{abstract}




\section{INTRODUCTION}

Low security hospital units (LSUs) were developed in England and Wales to bridge the gap between medium security hospital services and open settings (Dix, 2005; Dye et al., 2016; Prins, 2010; Davies, Maggs and Lewis, 2010). Approximately 2,500 low security beds were commissioned across England; there are 2,800 medium security beds in addition to 680 high security hospital places (The NHS Commissioning Board, 2013).The Department of Health (2002) set out the first national minimum standards for low security hospital services, which have been superseded by the Royal College of Psychiatrists' Quality Network for Forensic Mental Health Services (Tucker et al., 2012; Holder and Souza, 2016). There is, however, a paucity of evidence on low security patient characteristics and clinical outcomes.

\section{Clinical Characteristics}

A national survey identified 137 low security hospital units and found that patients in them are typically male (75\%), single (83\%) unemployed (91\%), have a diagnosis of schizophrenia $(62 \%)$ and stay for about one year (Pereira et al., 2006). One third of the patients had two or more complex needs (e.g. relating to challenging behaviour and substance misuse problems) and that patients stayed for approximately one year (mean 354 days). In a study of a single unit in the South of England, Beer et al. (2005) showed that approximately three-quarters had been admitted under provisions of the Mental Health Act 1983, 74\% of these under civil section (Section 2 or 3 ) and $26 \%$ under a section imposed by a criminal court (Section 37 or $37 / 41$ ); in most cases (57\%) there was no criminal offence relating to the admission studied.

\section{Clinical Outcomes}


There is a dearth of literature on clinical outcomes from low security hospitals. Using the Health of the Nation Outcome Scale (HoNOS; Wing et al., 1999) and the Global Assessment Scale (GAS; Endicott et al., 1976), administered on admission and discharge, Beer et al. (2007) found that improvements in these scales were associated with moves to lower levels of hospital security. The HoNOS-secure has since been developed for use in forensic mental health settings (Sugarman \& Walker, 2007; Dickens et al., 2007) and has been recommended as a routine outcome measure (Dickens et al., 2010; Shinkfield \& Ogloff, 2014).

Nevertheless, there is little consensus on outcome measurement in forensic mental health research (Chambers et al., 2009; Fitzpatrick et al., 2010), with more emphasis on measuring recidivism and mental health (Fitzpatrick et al., 2010) than social functioning or quality of life (Chambers et al., 2009). These reviews highlighted the utility and promise for including risk assessment tools, such as the HCR-20 (Webster et al., 1997), as an outcome measure as well as a tool for assisting assessment of risk of harm. A small, but significant, change in HCR-20 scores over time on Clinical and Risk Management subscales and total scores have been shown in an English high security hospital sample (Morrissey et al., 2014) and in individual items on these subscales with level of security need as measured on a 9point scale (Müller-Isberner et al., 2007).

Two of us previously evaluated the feasibility of a clinical case register as a means of systematically collecting routine outcome data at a low security hospital unit (Edworthy \& Khalifa, 2014). In brief, it was found that assessments were not always completed or recorded electronically and so staff were reminded of the importance of ensuring completion. In this study we aimed to describe the demographic and clinical characteristics of patients admitted to the unit after the register had been fully implemented, with any changes in clinical outcomes. Our research questions were what clinical changes would be apparent after the first 
six months of treatment and what clinical changes after the second six months for those who remained on the unit?

\section{METHOD}

The work was approved by the Trust's Research and Innovation Department as a service evaluation (NHS Health Research Authority, 2016). Patient confidentiality was maintained by assigning each patient an identity code and not recording patient identifiable data on the paper proforma or electronic case register.

\section{Setting}

'The unit' is an 84-bedded low security hospital which mainly draws patients from the East Midlands region of England. It has three wards for men with mental illness, one for women and one for intellectually disabled men. Multidisciplinary teams provide medical, psychological, occupational, educational and vocational programmes to promote recovery and rehabilitation and reduce risks of harm. Psychological interventions such anger management, substance misuse programmes, violence reduction, social problem solving and psychoeducation, are provided in groups. Other specialised interventions are provided individually.

\section{Sample}

Only men were included as the numbers of women were too small for separate analysis. All men resident on the unit on $1^{\text {st }}$ January $2011(n=44$; of whom, 17 had been resident less than 1 year, 13 less than 2 years, and 14 over 2 years) and all subsequent male admissions to the unit up to a census date of $31^{\text {st }}$ May 2013 were eligible. Only data relating to first admissions during this period were included, so men were not double-counted. 


\section{Data Collection}

Data were extracted from assessments recorded routinely by trained clinicians within the multi-disciplinary team on completion of each patient's Care Programme Approach review, held three months after admission (baseline) and at six monthly intervals thereafter. The proforma developed in the feasibility study was used for initial recording, completed within two months of the review record completion; in the event of missing data, additional information was requested from the clinicians. Information about offending histories was obtained from Police National Computer records as well as the clinical record.

\section{Outcome Measures}

The Health of the Nation Outcome Scale - secure (HoNOS-secure; Sugarman \& Walker, 2007) has twelve original items (1-12) which cover behaviour, impairment, symptoms and social functioning and an additional seven-item security scale items (A-G). Each item is rated on a five-point Likert scale from 0 (no problem) to 4 (severe problem). Item 11 'Problems with living conditions' was originally developed for community patients (Dickens et al., 2007) and was omitted for this study.

The Historical Clinical Risk-20 Version 2 (HCR-20; Webster et al., 1997) is a 20-item structured professional judgement tool for assessing the risk of future violence in criminal and psychiatric populations. Ten items relate to historical risk, five to clinical risk and five to risk management. Each item is scored as 0 absent, 1 possibly present and 2 definitely present. These scores produce three subtotals and an overall total score of up to 40 . 
Incident reporting: A Trust-wide standardised incident reporting form is used to record violent, aggressive and self-harm incidents. These data were provided by the Risk Management Department.

\section{Statistical Analysis}

Data were analysed using the Statistical Package for Social Science (SPSS) version 19. Frequencies were used to describe the sample. We used repeated measures t-tests to assess change in HoNOS-secure and HCR-20 ratings between baseline and 6 months, and 6 months and 12 months. This method was preferred to ANOVA to maximise the sample size because HoNOS-secure and HCR-20 ratings were available for fewer patients at 12 months.

Bonferroni corrections were applied by dividing the alpha level (0.05) by the number of tests conducted.

Individual effect sizes (ES), a method of assessing clinically meaningful change (Eisen et al., 2007), were computed by subtracting the individual score at time 2 ( 6 months) from the individual score at time ${ }_{1}$ (baseline) and dividing by the group standard deviation at time 1 $\left(s_{1}\right): E S=\left(t_{1}-t_{2}\right) / s_{1} t_{1}$. In accordance with Eisen et al (2007), effect sizes less than -0.50 were interpreted as a large decline, between -0.49 and 0.49 as no effect or a small effect, and greater than 0.50 as a medium to large improvement.

\section{RESULTS}

\section{Sample Characteristics}

Forty-four men were resident at the start of the study and 64 were subsequently admitted before the census date, yielding a total of 108 men. Mean age on admission was 34.3 years 
(standard deviation $[\mathrm{SD}]=10.5)$. Overall, $77(71 \%)$ identified as White, with and $31(29 \%)$ as from Black and Minority Ethnic (BME) groups. Most of the men were single (100, 93\%).

Twenty-eight men (26\%) had been admitted from a more secure hospital, 37 (34\%) from prison, $21(19 \%)$ from generic mental health services and $13(12 \%)$ from community forensic mental health services.

Most $(89,82 \%)$ had been convicted of an offence which had at least in part triggered this period of institutionalisation [an index offence]. The other 19 men had been referred by other forensic mental health inpatient services $(n=6)$, community forensic mental health services $(n=3)$, generic services $(n=6)$ and other $(n=4)$.

\section{Clinical Characteristics}

The clinical characteristics of the sample are summarised in Table 1 . Most $(67,62 \%)$ had a primary diagnosis of schizophrenia. Illicit drug misuse/dependence was the most prevalent secondary diagnosis $(26,24 \%)$. The median number of violent and non-violent offences across the lifetime was 2 (range 0-62) and 3 (range 0-63) respectively. Median age at first offence $(n=100)$ was 18 years (range $10-65$ years).

\section{TABLE 1 HERE}

By the end of May 2013, 77 men had been discharged: 28 (36\%) directly to the community, $21(27 \%)$ to generic psychiatric services, $15(19 \%)$ to a pre-discharge unit, $9(12 \%)$ to other secure hospitals and $4(5 \%)$ to other placements (e.g. prison, immigration detention centre), with a median length of stay of 491 days (IQR 279.5-752). 


\section{Outcomes}

\section{Inpatient incidents}

Ninety (83\%) patients had a least one incident recorded during admission (median 6.0, IQR 1-19); physical violence to others was the most common. There was no significant difference in number of incidents of violence or aggression between those who were discharged (median 6.0, IQR 1-18) and current inpatients (median 9.0, IQR 2-22; $\mathrm{U}=1030.5, \mathrm{Z}=-1.111, \mathrm{p}=$ 0.267). In addition, 30 (28\%) patients had self-harmed at least once during admission; 20 had a single episode, six had 2-4 episodes and four had 6-13 episodes of self-harm.

\section{HoNOS-Secure}

HoNOS-secure ratings from baseline to six months are shown in Table 2. Data at baseline and six months were available for 100 men. There was a significant reduction between baseline $($ mean $=10.9 ; \mathrm{SD}=5.8)$ and 6 month ratings $($ mean $=8.0 ; \mathrm{SD}=5.3)$ on the HoNOS 11-item subscale $(\mathrm{t}=4.896, \mathrm{df}=99, \mathrm{p}<0.001$, with a medium effect size $r=0.44)$. There were also reductions of medium effect sizes over the first six months in 'problem drinking or drug-taking' $(\mathrm{r}=0.30)$; 'problems with hallucinations and delusions' $(\mathrm{r}=0.36)$; 'problems with relationships' $(r=0.39)$; and the need for escort on leave beyond the secure perimeter $(\mathrm{r}$ $=0.41$ ). The latter was the only reduction in the seven security items, and there was no significant change overall on the security subscale.

Individual effect sizes for the changes in HoNOS at the second assessment (6 months after baseline) are shown in Table 3. Nearly half (44\%) demonstrated improvement on the 11-items used, while only $10 \%$ showed a deterioration. By contrast, just $30 \%$ showed improvement of medium or large effect on the security subscale and $26 \%$ showed an apparent deterioration. 
HoNOS-Secure data between 6 and 12 months were available for 63 men. Attrition occurred due to discharge prior to the 12 months assessment and missing data where assessments were not readily available. There was a significant reduction in the 11-item HoNOS score for this period $($ mean $=8.3 ; \mathrm{SD}=4.5$ to mean $=7.3 ; \mathrm{SD}=4.5 ; \mathrm{t}=2.136, \mathrm{df}=$ $62, \mathrm{p}=0.037$, with a small effect size $r=0.26$ ). Again, there was no significant change on the security subscale.

\section{TABLE 3 HERE}

Our baseline ratings for some patients were taken several months after admission, which could substantially affect apparent change over time following admission, so we repeated the analyses for patients with baseline ratings taken within three months of admission. Data at baseline and six months were available for 71 men. The items which were statistically significant in the previous method (as shown in Table 2) remained statistically significant in the new method. The significant reduction between baseline (mean 11.7; SD 6.1) and 6 month ratings (mean 7.7; SD 5.0) on the 11-item HoNOS, for example, was similar $(\mathrm{t}=$ $5.629, \mathrm{df}=70, \mathrm{p}<0.001)$, but with a slightly larger effect size $(r=0.56)$. In addition, significant reductions over the first six months in 'overactive, aggressive, disruptive or agitated behaviour' $(\mathrm{t}=3.288, \mathrm{df}=70, \mathrm{p}=0.002, \mathrm{r}=0.37)$ and 'cognitive problems' $(\mathrm{t}=$ $3.539, \mathrm{df}=70, \mathrm{p}=0.001, \mathrm{r}=0.39)$ were noted.

HoNOS-Secure data between 6 and 12 months for the late baseline men were available for 42 men. Attrition occurred due to discharge prior to the 12 months assessment and missing data where assessments were not readily available. There was a significant reduction on the HoNOS 11-item subscale for this period $($ mean $=7.9 ; \mathrm{SD}=4.5$ to mean $=6.5 ; \mathrm{SD}=4.4 ; \mathrm{t}=$ 
2.531, $\mathrm{df}=41, \mathrm{p}=0.015$, with a medium effect size $r=0.37)$. Again, there was no significant change on the security subscale.

\section{HCR-20}

HCR-20 data at baseline and six months were available for 72 men (see Table 4). The HCR-20 total scores at baseline and six months ranged from 10 to 37 (Mean $=27.01 ; \mathrm{SD}=$ 5.69) and from 12 to 37 (Mean $=27.06 ; \mathrm{SD}=5.61)$ respectively. There were no significant group changes from baseline to 6 months in total HCR-20 score $(\mathrm{t}=-0.104, \mathrm{df}=71, \mathrm{p}=$ 0.918 ) or the subscale scores separately (Historical $\mathrm{t}=-0.196, \mathrm{df}=71, \mathrm{p}=0.236$; Clinical $\mathrm{t}=$ 0.719, $\mathrm{df}=71, \mathrm{p}=0.474 ;$ Risk Management $\mathrm{t}=0.514, \mathrm{df}=71, \mathrm{p}=0.609)$. HCR-20 data at 12 months was only available for 27 men and is not considered further except to say that scores remained similar between six and twelve months.

\section{TABLE 4 HERE}

Between baseline and six months, the HCR-20 total scores were unchanged for 29 men (40\%), decreased for 22 men (31\%) by up to 9 points and increased for 21 men (29\%) by up to 12 points. Given the limited scope for change, the percentage of men who were rated at 2 (definitely present) at baseline and 6 months is also shown in Table 4. Individual effect sizes indicate that 11 men $(15 \%)$ showed good overall improvement at six months on comparing their HCR-20 rating at baseline with the score six months later (see Table 5).

Conversely, $10(14 \%)$ showed the increase in scores at six months, but most were unchanged (71\%). The largest effect sizes occurred on the Risk Management subscale (17, 24\% lower; $12,17 \%$ higher at six months). 


\section{TABLE 5 HERE}

\section{DISCUSSION}

We found a significant reduction in HoNOS scores from baseline to six months, except in its security subscale. In line with this, the HCR-20 group mean scores changed little, notwithstanding some individual changes.

\section{Clinical characteristics}

Our sample was typical of low security hospital patients in most respects - most being male, white, single and diagnosed with schizophrenia (Beer et al., 2005; Pereria et al., 2006). The overrepresentation of people from BME groups (29\%) when compared to the general population (14\%) and the County's population of 5\% (Office for National Statistics, 2011) also replicated findings from other studies (e.g., Coid et al., 2007; Pereria et al., 2006). By contrast, length of stay for our sample was higher than that reported in some other studies (e.g., Pereira et al., 2006; Beer et al., 2007), although the median length of stay was similar to the 428 days reported in Shah et al's (2011) evaluation of a medium secure unit. In the latter study, a high proportion of patients had been admitted under the provisions of the Mental Health Act with restriction on discharge orders. Over $40 \%$ of the patients in our sample had been under restrictions on discharge compared with the $25 \%$ reported by Beer et al. (2005) and $34 \%$ by Pereira et al. (2006), while we also had many more patients convicted of an index offence ( $82 \%)$ compared with Beer's group (43\%). It is likely that as units become more established they will accept more complex cases.

\section{Clinical Outcomes}

A major finding from this study is the reduction in the 11-item HoNOS score between baseline and six months, and a further reduction between six months and 12 months. The 
effect size indicated, however, that fewer than half had made a clinically important improvement at six months.

The 7-item subscale of HoNOS specific to security did not change, suggesting that security needs and perceived risk levels of the sample remained stable over twelve months, although approximately one-third of patients improved as measured by their individual scores. Sugarman et al (2009) also with a low security cohort, similarly found no significant change in the HoNOS-secure subscale, albeit over a shorter time, despite noting changes over time in the symptoms. Our baseline scores on the secure subscale were similar to those in Dickens et al (2010), who did report significant improvements, but over a longer period. In line with this, in our sample, the risk status as measured by the HCR-20 did not change significantly in the six or twelve months time intervals. The literature also suggests that longer intervals may be needed for detecting positive change. Olsson et al (2013), for example, found reductions in scores on some items from the clinical and risk management scales after 9 months and on all but two risk items after a mean of 43 months. Morrissey et al (2014) found that the mutable - clinical and risk management items - showed improvement over a five year period in a high security hospital. These findings together suggest that the HCR-20 is sensitive to change, but over a longer period than the six and twelve month period we adopted. Further, change may have been obscured by the increase in score recorded for some patients. There is an assumption that this is indicative of increased risk, but during the first six months of any secure admission, increase may better indicate improved recognition and recording of risk factors rather than any deterioration and could, thus, be a valuable precursor to improvement. The clincial context of the scores should always be considered. As the relationship between HCR-20 scores and adverse outcomes among those discharged from secure hospitals has been demonstrated (Doyle \& Dolan, 2006; Gray et al., 2008) it is clearly worth persisting with this measure. 
Besides, the use of tools to measure such outcomes as treatment completion and recovery is also worthy of consideration when measuring change in secure settings (Davoren et al., 2013; 2015). Whilst there remains a need to identify robust tools to measure change in such settings (Shinkfield \& Ogloff, 2014), clinician-rated tools remain susceptible to bias.

\section{Strengths and limitations of study}

The importance of measuring clinical outcomes in healthcare settings is accepted (Edworthy \& Khalifa, 2014), but choice of a meaningful set is more difficult, as is finding the clinical time to complete the assessments. An important strength of this work is that we were able to use routinely collected clincal data to conduct a systematic analysis of outcomes from admission to a low security hosital.

These data were from just one hospital and may not be generalisable, although comparisons with other studies are promising in this respect. Further, there were no women in our sample, and some male subgroups were absent - e.g. men with intellectual disabilities. Since the clinical database was implemented in 2011 , some of the outcome measures have been superseded by newer versions (e.g. the HCR-20 Version 2 (Webster et al., 1997) by the HCR20 Version 3 (Douglas et al., 2013)). There are differences between the HCR-20 Versions 2 and 3 (Douglas et al., 2014), so we used the newer version, but this meant that some items were re-scored retrospectively for the purpose of this study.

We assessed clinically meaningful change using individual effect sizes. Other methods require population norms (Eisen et al., 2007; O'Shea \& Dickens, 2015) but these are not available for the HCR-20 and HONOS-Secure and require suitable proxy norms. O'Shea and Dickens (2015) used HCR-20 ratings at disharge from medium security but, given the higher security level, this would not be suitable for our evaluation of low security patients. 
The first (baseline) assessment for some patients did not occur until several months after admission. Therefore, this may not be classed as a true baseline measure. Our study is not, however, unique in this regard (e.g. see Dickens \& O'Shea, 2017). We re-analysed the HoNOS scores for a subgroup of patients with baseline assessments within three months of admission and found improvements at six months on two additional items. Therefore, we recommend that future studies use assessments of new admissions for baseline and not include patients who have been in the hospital for some time. While no significant changes were found in the HCR-20 over time, we did not use this method to reanalyse the HCR-20 data because the sample size was reduced substantially.

\section{References}

Beer, D., Spiller, M. J., Pickard, M., Gravestock, S., McGovern, P., Leese, M., \& ... Bouras, N. (2005). Low secure units: Factors predicting delayed discharge. Journal of Forensic Psychiatry \& Psychology, 16(4), 621-637.

Beer, M.D., Tighe, J., Ratnajothy, K., \& Masterson, D. (2007). Predicting outcome in low secure environments: a case series from one low secure unit. Journal of Psychiatric Intensive Care, 3(2), 85-92.

Chambers, J. R., Yiend, J., Barrett, B., Burns, T., Doll, H., Fazel, S., \& ... Fitzpatrick, R. (2009). Outcome measures used in forensic mental health research: a structured review. Criminal Behaviour \& Mental Health, 19(1), 9-27.

Coid, J., Hickey, N., Kahtan, N., Zhang, T., \& Yang, M. (2007). Patients discharged from medium secure forensic psychiatry services: reconvictions and risk factors. The British Journal of Psychiatry, 190(3), 223-229. 
Davies, J., Maggs, R.G., \& Lewis, R. (2010). The Development of a UK Low Secure Service: Philosophy, Training, Supervision and Evaluation. International Journal of Forensic Mental Health, 9(4), 334-342.

Davoren, M., Abidin, Z., Naughton, L., Gibbons, O., Nulty, A., Wright, B. \& Kennedy, H.G. (2013). Prospective study of factors influencing conditional discharge from a forensic hospital: the DUNDRUM-3 programme completion and DUNDRUM-4 recovery structured professional judgement instruments and risk. BMC Psychiatry, 13:185. DOI: 10.1186/1471244X-13-185.

Davoren, M., Byrne, O., O’Connell, P., O’Neill, H., O’Reilly, K. \& Kennedy, H.G. (2015). Factors affecting length of stay in forensic hospital setting: need for therapeutic security and course of admission. BMC Psychiatry, 15:301. DOI: 10.1186/s12888-015-0686-4.

Department of Health. (2002). Mental Health Policy Implementation Guide: National Minimum Standards for General Adult Services in Psychiatric Intensive Care units (PICU) and Low Secure Environments. London, UK: Department of Health.

Department of Health. (2008). Using the Commissioning for Quality and Innovation (CQUIN) Payment Framework. London, UK: Department of Health.

Dickens, G.L \& O'Shea, L.E. (2017): Reliable and Clinically Significant Change in Outcomes for Forensic Mental Health Inpatients: Use of the HoNOS-Secure, International Journal of Forensic Mental Health, DOI: 10.1080/14999013.2017.1286415

Dickens, G., Sugarman, P., Picchioni, M., \& Long, C. (2010). HoNOS-Secure: tracking risk and recovery for men in secure care. British Journal of Forensic Practice, 12(4), 36-46.

Dickens, G. L., Sugarman, P., \& Walker, L. (2007). HoNOS-secure: A reliable outcome measure for users of secure and forensic mental health services. Journal of Forensic Psychiatry \& Psychology, 18(4), 507-514. 
Dix, R. (2005). Psychiatric intensive care and low secure units past, present and future introducing the Journal of Psychiatric Intensive Care. Journal of Psychiatric Intensive Care, $1(1), 1-2$.

Douglas, K. S., Hart, S. D., Webster, C. D., \& Belfrage, H. (2013). HCR-20V3: Assessing risk for violence - User guide. Burnaby, Canada: Mental Health, Law, and Policy Institute, Simon Fraser University.

Douglas, K. S., Hart, S. D., Webster, C. D., Belfrage, H., Guy, L. S., \& Wilson, C. M. (2014) Historical-Clinical-Risk Management-20, Version 3 (HCR-20V3): Development and Overview, International Journal of Forensic Mental Health, 13(2), 93-108.

Doyle, M., \& Dolan, M. (2006). Predicting community violence from patients discharged from mental health services. British Journal of Psychiatry, 189(6), 520-526.

Dye, S., Smyth, L., \& Pereira, S. (2016). Locked rehabilitation: a need for clarification. BJPsych Bulletin, 40, 1 - 4.

Edworthy, R., \& Khalifa, N. (2014). Development of a clinical case register for a low secure service: A feasibility study. The British Journal of Forensic Practice, 16(1), 58-67.

Endicott, J., Spitzer, R.L., Fleiss, J.L., \& Cohen, J. (1976). The Global Assessment Scale. A procedure for measuring overall severity of psychiatric disturbance. Archives of General Psychiatry, 33(6), 766-771.

Fitzpatrick, R., Chambers, J., Burns, T., Doll, H., Fazel, S., Jenkinson, C., \& ... Yiend, J. (2010). A systematic review of outcome measures used in forensic mental health research with consensus panel opinion. Health Technology Assessment (Winchester, England), 14(18), $1-94$.

Gray, N. S., Taylor, J., \& Snowden, R. J. (2008). Predicting violent reconvictions using the HCR-20. The British Journal of Psychiatry, 192, 384-387. 
Holder, S. \& Souza, R. (eds) (2016). Standards for Forensic Mental Health Services: Low and Medium Secure Care (CCQI publication number: CCQI 234). Royal College of Psychiatrists Centre for Quality Improvement.

Morrissey, C., Beeley, C., \& Milton, J. (2014). Longitudinal HCR-20 scores in a high-secure psychiatric hospital. Criminal Behaviour \& Mental Health, 24(3), 169-180.

Müller-Isberner, R., Webster, C. D., \& Gretenkord, L. (2007). Measuring progress in hospital order treatment: relationship between levels of security and $\mathrm{C}$ and R scores of the HCR20. International Journal of Forensic Mental Health, 6, 113-121.

The NHS Commissioning Board. (2013). NHS Standard Contract for Medium and Low Secure Mental Health Services (Adults) Schedule 2 - Service Specifications. Retrieved from http://www.england.nhs.uk/wp-content/uploads/2013/06/c03-med-low-sec-mh.pdf

NHS Health Research Authority (2016) Defining Research. Accessed March 31, 2017 from http://www.hra.nhs.uk/documents/2016/06/defining-research

O'Shea, L. E., \& Dickens, G. L. (2015). The HCR-20 as a measure of reliable and clinically significant change in violence risk among secure psychiatric inpatients. Comprehensive psychiatry, 62, 132-140.

Office for National Statistics. (2011). Census: Aggregate data (England and Wales) [computer file]. UK Data Service Census Support. Retrieved from: http://infuse.mimas.ac.uk

Olsson, H., Strand, S., Kristiansen, L., Sjöling, M., \& Asplund, K. (2013). Decreased risk for violence in patients admitted to forensic care, measured with the HCR-20. Archives of Psychiatric Nursing, 27, 191-197.

Pereira, S., Dawson, P., \& Sarsam, M. (2006). The National Survey of PICU and Low Secure Services: 1. Patient characteristics. Journal of Psychiatric Intensive Care. 2(1), 7-12.

Prins, H. (2010) Offenders, Deviants or Patients? Explorations in Clinical Criminology, London: Routledge 
Shah, A., Waldron, G., Boast, N., Coid, J. W., \& Ullrich, S. (2011). Factors associated with length of admission at a medium secure forensic psychiatric unit. Journal of Forensic Psychiatry \& Psychology, 22(4), 496-512.

Shinkfield, G., \& Ogloff, J. (2014). A Review and Analysis of Routine Outcome Measures for Forensic Mental Health Services. International Journal of Forensic Mental Health, 13(3), 252-271.

Sugarman, P., \& Walker, L. (2007). HoNOS-Secure, Version 2b. Retrieved from http:// www.rcpsych.ac.uk/researchandtrainingunit/honos/secure.aspx

Sugarman, P., Walker, L., \& Dickens, G. (2009). Managing outcome performance in mental health using HoNOS: experience at St Andrew's Healthcare. Psychiatric Bulletin, 33(8), 285288.

Tucker, S., Iqbal, M., \& Holder, S. (eds) (2012). Standards for Low Secure Services (CCQI publication number: CCQI 130). Royal College of Psychiatrists Centre for Quality Improvement.

Webster, C. D., Douglas, K. S., Eaves, D., \& Hart, S. D. (1997). HCR-20: Assessing risk for violence, version 2. Burnaby, Canada: Mental Health, Law, and Policy Institute, Simon Fraser University.

Wing, J., Curtis, R.H., \& Beevor, A. (1999). Health of the Nation Outcome Scales. British Journal of Psychiatry. 174, 432-434. 
Table 1: Clinical Characteristics

\begin{tabular}{|c|c|c|c|}
\hline Variable & $\begin{array}{c}\text { Inpatients } \\
(\mathrm{n}=31)\end{array}$ & $\begin{array}{c}\text { Discharged } \\
(\mathrm{n}=77)\end{array}$ & $\begin{array}{c}\text { Total } \\
(\mathrm{n}=108)\end{array}$ \\
\hline \multicolumn{4}{|l|}{ Source of Referral } \\
\hline Forensic Services & $9(29.0 \%)$ & $19(24.7 \%)$ & $28(25.9 \%)$ \\
\hline Community Forensic Services & $5(16.1 \%)$ & $8(10.4 \%)$ & $13(12.0 \%)$ \\
\hline Local Services & $6(19.4 \%)$ & $15(19.5 \%)$ & $21(19.4 \%)$ \\
\hline Prison & $9(29.0 \%)$ & $28(36.4 \%)$ & $37(34.3 \%)$ \\
\hline Courts & $0(0 \%)$ & $2(2.6 \%)$ & $2(1.9 \%)$ \\
\hline Other (e.g., Recalled) & $2(6.5 \%)$ & $5(6.5 \%)$ & $7(6.5 \%)$ \\
\hline \multicolumn{4}{|l|}{ Mental Health Act Section ${ }^{\mathrm{a}}$} \\
\hline Section 3 & $11(35.5 \%)$ & $27(35.5 \%)$ & $38(35.5 \%)$ \\
\hline Section 37 & $6(19.4 \%)$ & $16(21.1 \%)$ & $22(20.6 \%)$ \\
\hline Section $37 / 41$ & $11(35.5 \%)$ & $18(23.7 \%)$ & $29(27.1 \%)$ \\
\hline Section $48 / 49$ & $0(0 \%)$ & $5(6.6 \%)$ & $5(4.7 \%)$ \\
\hline Section $47 / 49$ & $3(9.7 \%)$ & $8(10.5 \%)$ & $11(10.3 \%)$ \\
\hline Other & $0(0 \%)$ & $2(2.6 \%)$ & $2(1.9 \%)$ \\
\hline \multicolumn{4}{|l|}{ Community Treatment Order Recall (CTO) } \\
\hline Yes & $2(6.5 \%)$ & $6(7.8 \%)$ & $8(7.4 \%)$ \\
\hline No & $29(93.5 \%)$ & $71(92.2 \%)$ & $100(92.6 \%)$ \\
\hline \multicolumn{4}{|l|}{ Primary ICD-10 Diagnosis } \\
\hline Schizophrenia & $17(54.8 \%)$ & $50(64.9 \%)$ & $67(62.0 \%)$ \\
\hline Delusional disorders & $1(3.2 \%)$ & $5(6.5 \%)$ & $6(5.6 \%)$ \\
\hline Schizoaffective disorder & $3(9.7 \%)$ & $4(5.2 \%)$ & $7(6.5 \%)$ \\
\hline Bipolar affective disorder & $1(3.2 \%)$ & $5(6.5 \%)$ & $6(5.6 \%)$ \\
\hline Depressive disorder & $0(0 \%)$ & $3(3.9 \%)$ & $3(2.8 \%)$ \\
\hline Personality disorder & $4(12.9 \%)$ & $6(7.8 \%)$ & $10(9.3 \%)$ \\
\hline Intellectual disability & $3(9.7 \%)$ & $3(3.9 \%)$ & $6(5.6 \%)$ \\
\hline Pervasive developmental disorder & $2(6.5 \%)$ & $1(1.3 \%)$ & $3(2.8 \%)$ \\
\hline \multicolumn{4}{|l|}{ Secondary ICD-10 Diagnosis } \\
\hline Illicit drug misuse/dependence & $3(9.7 \%)$ & $23(29.9 \%)$ & $26(24.1 \%)$ \\
\hline Alcohol misuse/dependence & $1(3.2 \%)$ & $8(10.5 \%)$ & $9(8.3 \%)$ \\
\hline Organic mental disorder & $0(0 \%)$ & $2(2.6 \%)$ & $2(1.9 \%)$ \\
\hline Personality disorder & $3(9.7 \%)$ & $10(13.0 \%)$ & $13(12.0 \%)$ \\
\hline Intellectual disability & $6(19.4 \%)$ & $1(1.3 \%)$ & $7(6.5 \%)$ \\
\hline Other & $1(3.2 \%)$ & $5(6.5 \%)$ & $6(5.6 \%)$ \\
\hline \multicolumn{4}{|l|}{ Admission Unit } \\
\hline Acute Admission & $15(48.4 \%)$ & $54(70.1 \%)$ & $69(63.9 \%)$ \\
\hline Rehabilitation & $3(9.7 \%)$ & $16(20.8 \%)$ & $19(17.6 \%)$ \\
\hline Longer Term Rehabilitation & $6(19.4 \%)$ & $3(3.9 \%)$ & $9(8.3 \%)$ \\
\hline Learning Disability Service & $7(22.6 \%)$ & $4(5.2 \%)$ & $11(10.2 \%)$ \\
\hline
\end{tabular}




\begin{tabular}{lccc}
\hline Index Offence Type & & & \\
Violent & $16(51.6 \%)$ & $47(61.0 \%)$ & $63(58.3 \%)$ \\
Non-violent & $2(6.5 \%)$ & $12(15.6 \%)$ & $14(13.0 \%)$ \\
Sexual & $6(19.4 \%)$ & $1(1.3 \%)$ & $7(6.5 \%)$ \\
Violent and Sexual & $3(9.7 \%)$ & $2(2.6 \%)$ & $5(4.6 \%)$ \\
Not applicable & $4(12.9 \%)$ & $15(19.5 \%)$ & $19(17.6 \%)$ \\
\hline
\end{tabular}

Note: ${ }^{\text {a }} \mathrm{n}$ Discharged $=76, \mathrm{n}$ Total $=107$ 
Table 2: HoNOS-secure ratings from baseline to six months

\begin{tabular}{|c|c|c|c|c|c|c|}
\hline \multirow[t]{2}{*}{ HoNOS-Secure } & \multicolumn{2}{|c|}{ Baseline $(\mathrm{N}=100)$} & \multicolumn{2}{|c|}{6 months $(\mathrm{N}=100)$} & \multirow{2}{*}{$d f=99$} & \multirow[t]{2}{*}{$P$} \\
\hline & Mean $(S D)$ & $\begin{array}{c}\text { Number of men } \\
\text { rated }>=2(\%)\end{array}$ & Mean $(S D)$ & $\begin{array}{c}\text { Number of men } \\
\text { rated }>=2(\%)\end{array}$ & & \\
\hline $\begin{array}{l}1 \text { Overactive, aggressive, disruptive or } \\
\text { agitated behaviour }\end{array}$ & $1.1(1.3)$ & 34 & $0.7(1.0)$ & 21 & 2.855 & 0.005 \\
\hline 2 Non-accidental self-injury & $0.2(0.6)$ & 7 & $0.2(0.6)$ & 6 & 0.638 & 0.525 \\
\hline 3 Problem drinking or drug-taking & $0.5(1.0)$ & 16 & $0.1(0.5)$ & 5 & 3.108 & 0.002 \\
\hline 4 Cognitive problems & $1.0(1.1)$ & 29 & $0.6(0.9)$ & 19 & 3.023 & 0.003 \\
\hline 5 Physical illness or disability problems & $0.9(1.0)$ & 24 & $0.8(1.0)$ & 26 & 0.463 & 0.644 \\
\hline 6 Problems with hallucinations and delusions & $1.5(1.4)$ & 52 & $1.1(1.2)$ & 35 & 3.785 & $<0.001$ \\
\hline 7 Problems with depressed mood & $0.7(0.8)$ & 16 & $0.6(0.7)$ & 13 & 2.182 & 0.031 \\
\hline 8 Other mental and behavioural problems & $1.3(1.3)$ & 49 & $1.1(1.2)$ & 40 & 2.090 & 0.039 \\
\hline 9 Problems with relationships & $1.9(1.1)$ & 72 & $1.4(1.2)$ & 52 & 4.263 & 0.001 \\
\hline 10 Problems with activities of daily living & $1.1(1.1)$ & 35 & $0.9(1.0)$ & 30 & 2.245 & 0.027 \\
\hline 12 Problems with occupation and activities & $0.8(1.0)$ & 25 & $0.6(0.8)$ & 20 & 1.657 & 0.101 \\
\hline \multirow[t]{2}{*}{11 -item subscale (1-10 \& 12) } & $10.9(5.8)$ & - & $8.0(5.3)$ & - & 4.896 & $<0.001$ \\
\hline & & $\begin{array}{l}\text { Number of men } \\
\text { rated }>=1(\%)\end{array}$ & & $\begin{array}{l}\text { Number of men } \\
\text { rated }>=1(\%)\end{array}$ & & \\
\hline
\end{tabular}




\begin{tabular}{|c|c|c|c|c|c|c|}
\hline A risk of harm to adults or children & $2.1(1.1)$ & 90 & $2.3(1.0)$ & 95 & -1.662 & 0.100 \\
\hline $\mathrm{B}$ risk of self-harm (deliberate or accidental) & $1.1(1.0)$ & 73 & $1.4(1.2)$ & 73 & -2.691 & 0.008 \\
\hline $\mathrm{C}$ need for building security to prevent escape & $1.8(0.7)$ & 90 & $1.8(0.6)$ & 92 & 0.000 & 1.000 \\
\hline D need for a safely staffed living environment & $2.2(0.7)$ & 99 & $2.1(0.6)$ & 99 & 1.318 & 0.191 \\
\hline $\begin{array}{l}\text { E need for escort on leave (beyond secure } \\
\text { perimeter) }\end{array}$ & $1.7(1.1)$ & 83 & $1.2(0.9)$ & 73 & 4.469 & $<0.001$ \\
\hline F risk to individual from others & $1.1(0.9)$ & 72 & $1.2(1.0)$ & 72 & -1.330 & 0.186 \\
\hline $\mathrm{G}$ need for risk management procedures & $1.9(0.7)$ & 99 & $1.9(0.5)$ & 99 & 0.000 & 1.000 \\
\hline Security subscale (A-G) & $11.9(3.5)$ & - & $11.9(3.5)$ & - & 0.000 & 1.000 \\
\hline
\end{tabular}

Note: Item 11 'Problems with living conditions' is not rated; Bonferoni correction $(0.05 / 20=0.0025)$ 
Table 3: Proportions of deterioration or improvement between HoNOS baseline and 6 months according to individual effect size

\begin{tabular}{lccc}
\hline $\mathrm{N}=100$ & $\begin{array}{c}\text { Large decline } \\
(\mathrm{ES}<-0.50)\end{array}$ & $\begin{array}{c}\text { No effect to small } \\
\text { effect } \\
(\mathrm{ES}-0.49 \text { to 0.49) }\end{array}$ & $\begin{array}{c}\text { Medium or large effect } \\
(\mathrm{ES}>0.50)\end{array}$ \\
\hline 11-item HoNOS* (1-10 \& 12) & 10 & 46 & 44 \\
Security subscale (A-G) & 26 & 44 & 30 \\
\end{tabular}

*The community living item was removed from the original 12 -item scale 
Table 4: HCR-20 ratings from baseline to six months

\begin{tabular}{|c|c|c|c|c|c|c|}
\hline$\overline{\text { HCR-20 }}$ & $\begin{array}{c}\text { Baseline } \\
\text { Mean (SD) }\end{array}$ & $\begin{array}{c}\text { Baseline } \\
\text { Number of men } \\
\text { rated "2" (\%) }\end{array}$ & $\begin{array}{c}6 \text { months } \\
\text { Mean (SD) }\end{array}$ & $\begin{array}{c}6 \text { months } \\
\text { Number of men } \\
\text { rated "2" (\%) }\end{array}$ & $t$ & $P$ \\
\hline & $N=72$ & & $N=72$ & & $d f=71$ & \\
\hline H 1: Previous violence & $1.96(0.20)$ & $69(95.8)$ & $1.99(0.12)$ & $71(98.6)$ & -1.424 & 0.159 \\
\hline H 2: Young age at first violent incident & $1.28(0.83)$ & $37(51.4)$ & $1.24(0.80)$ & $33(45.8)$ & 0.830 & 0.409 \\
\hline H 3: Relationship instability & $1.60(0.66)$ & $50(69.4)$ & $1.54(0.67)$ & $46(63.9)$ & 1.070 & 0.288 \\
\hline H 4: Employment problems & $1.56(0.63)$ & $45(62.5)$ & $1.64(0.56)$ & $49(68.1)$ & -1.424 & 0.159 \\
\hline H 5: Substance use problems & $1.69(0.66)$ & $58(80.6)$ & $1.71(0.64)$ & $58(80.6)$ & -0.445 & 0.658 \\
\hline H 6: Major mental illness & $1.88(0.41)$ & $65(90.3)$ & $1.89(0.40)$ & $66(91.7)$ & -1.000 & 0.321 \\
\hline H 7: Psychopathy & $0.07(0.26)$ & $0(0.0)$ & $0.07(0.26)$ & $0(0.0)$ & 0.000 & 1.000 \\
\hline H 8: Early maladjustment & $1.40(0.78)$ & $42(58.3)$ & $1.44(0.75)$ & $43(59.7)$ & -0.772 & 0.442 \\
\hline H 9: Personality Disorder & $0.71(0.78)$ & $14(19.4)$ & $0.79(0.79)$ & $16(22.2)$ & -1.229 & 0.223 \\
\hline H 10: Prior supervision failure & $1.75(0.58)$ & $59(81.9)$ & $1.79(0.56)$ & $62(86.1)$ & -1.757 & 0.083 \\
\hline H: Total & $13.88(3.03)$ & & $14.1(2.87)$ & & -1.196 & 0.236 \\
\hline C 1: Lack of insight & $1.64(0.64)$ & $52(72.2)$ & $1.58(0.62)$ & $47(65.3)$ & 0.815 & 0.418 \\
\hline C 2: Negative attitudes & $1.13(0.77)$ & $26(36.1)$ & $1.14(0.76)$ & $26(36.1)$ & -0.217 & 0.829 \\
\hline C 3: Active symptoms of major mental illness & $1.24(0.87)$ & $37(51.4)$ & $1.22(0.83)$ & $34(47.2)$ & 0.191 & 0.849 \\
\hline C 4: Impulsivity & $1.26(0.82)$ & $36(50.0)$ & $1.24(0.81)$ & $34(47.2)$ & 0.497 & 0.620 \\
\hline
\end{tabular}




\begin{tabular}{|c|c|c|c|c|c|c|}
\hline C 5: Unresponsive to treatment & $1.25(0.77)$ & $32(44.4)$ & $1.19(0.74)$ & $28(38.9)$ & 0.728 & 0.469 \\
\hline C: Total & $6.51(2.52)$ & & $6.38(2.59)$ & & 0.719 & 0.474 \\
\hline R 1: Plans lack feasibility & $1.24(0.78)$ & $32(44.4)$ & $1.17(0.77)$ & $28(38.9)$ & 0.843 & 0.402 \\
\hline R 2: Exposure to destabilisers & $1.53(0.69)$ & $46(63.9)$ & $1.49(0.75)$ & $46(63.9)$ & 0.536 & 0.594 \\
\hline R 3: Lack of personal support & $1.15(0.80)$ & $29(40.3)$ & $1.10(0.83)$ & $28(38.9)$ & 0.815 & 0.418 \\
\hline R 4: Noncompliance with remediation attempts & $1.31(0.80)$ & $37(51.4)$ & $1.22(0.77)$ & $31(43.1)$ & 1.029 & 0.307 \\
\hline R 5: Stress & $1.67(0.61)$ & $53(73.6)$ & $1.68(0.58)$ & $53(73.6)$ & -0.257 & 0.798 \\
\hline R: Total & $6.78(2.45)$ & & $6.64(2.39)$ & & 0.514 & 0.609 \\
\hline HCR-20 Total & 27.01 (5.69) & & $27.06(5.16)$ & & -0.104 & 0.918 \\
\hline
\end{tabular}


Table 5: Proportions of deterioration or improvement between HCR-20 baseline and 6 months according to individual effect size

\begin{tabular}{lccc}
\hline $\mathrm{N}=72$ & $\begin{array}{c}\text { Large decline } \\
(\mathrm{ES}<-0.50)\end{array}$ & $\begin{array}{c}\text { No effect to small } \\
\text { effect } \\
(\mathrm{ES}-0.49 \text { to } 0.49)\end{array}$ & $\begin{array}{c}\text { Medium or large effect } \\
(\mathrm{ES}>0.50)\end{array}$ \\
\hline Historical & $7(9.7 \%)$ & $61(84.7 \%)$ & $4(5.6 \%)$ \\
Clinical & $5(6.9 \%)$ & $55(76.4 \%)$ & $12(16.7 \%)$ \\
Risk Management & $12(16.7 \%)$ & $43(59.7 \%)$ & $17(23.6 \%)$ \\
HCR-20 Total & $10(13.9 \%)$ & $51(70.8 \%)$ & $11(15.3 \%)$ \\
\hline
\end{tabular}

